\title{
Incidence and Outcomes of Acute Kidney Injury in COVID-19: A Systematic Review
}

\author{
Rupesh Raina ${ }^{a, b}$ Zubin A. Mahajan ${ }^{a}$ Prabhav Vasistha ${ }^{a}$ Ronith Chakraborty ${ }^{a, b}$ \\ Krishna Mukunda ${ }^{c, e}$ Abhishek Tibrewal $^{a}$ Javier A. Neyra ${ }^{d}$ \\ aDepartment of Nephrology, Akron Nephrology Associates/Cleveland Clinic Akron General, Akron, OH, USA; \\ bepartment of Nephrology, Akron Children's Hospital, Akron, OH, USA; 'A kron Nephrology Associates/Cleveland \\ Clinic Akron General, Akron, OH, USA; ${ }^{\mathrm{d} D i v i s i o n}$ of Nephrology, Bone and Mineral Metabolism, University of \\ Kentucky Medical Center, Lexington, KY, USA; ${ }^{e}$ Department of Biomedical Engineering, Johns Hopkins University, \\ Baltimore, MD, USA
}

\section{Keywords}

COVID-19 · Acute kidney injury · Kidney replacement therapy · Epidemiology · Nephrology

\begin{abstract}
Background and Objectives: The recent worldwide pandemic of COVID-19 has been a serious, multidimensional problem that has left a detrimental worldwide impact on individuals of all ages and several organ systems. The typical manifestation of kidney involvement is acute kidney injury (AKI); however, there is a lack of consensus data regarding AKI epidemiology in COVID-19. This systematic literature review aims to bridge this knowledge gap. Design, Setting, Participants, and Measurements: MEDLINE and Cochrane library were systematically searched for the literature related to AKI in COVID-19 patients of all ages. MedRxIV was searched for relevant unpublished manuscripts. Two reviewers independently assessed the literature on the incidence of AKI and mortality, extracting the need for kidney replacement therapy (KRT). Results: Sixty studies ( $n=43,871$ patients) were included in this review. The pooled incidence of AKI among COVID-19 patients was $19.45 \%$ (95\% confidence intervals [95\% Cl]: 14.63-24.77\%), while the pooled incidence
\end{abstract}

of AKI COVID-19 patients requiring KRT was 39.04\% (16.38$64.57 \%)$. The pooled proportion of COVID+ patients was significantly lower at $8.83 \%$ (5.64\% to $12 / 66 \%)$. The overall mortality of COVID-19 patients was calculated to be $17.71 \%$ (95\% Cl: 11.49-24.93\%), while the mortality among patients with AKI was higher at 54.24\% (95\% Cl: 44.70-63.63\%). Conclusion: This comprehensive systematic review summarizes the available literature pertaining to AKI epidemiology in COVID-19 patients and highlights the incidence, associated mortality, and the need for KRT in this susceptible population.

(C) 2021 S. Karger AG, Basel

\section{Introduction}

The COVID-19 pandemic is a serious, multidimensional problem with tremendous detrimental consequences for healthcare, occupation, and economy [1-3]. First identified as a cluster of pneumonia cases of unknown origin in Wuhan, China in December 2019, the severe acute respiratory syndrome coronavirus 2 (SARS-

Rupesh Raina and Zubin A. Mahajan are co-first authors. karger@karger.com www.karger.com/bpu

(C) 2021 S. Karger AG, Base

Karger"
Correspondence to:

Rupesh Raina, rraina@ akronchildrens.org 
$\mathrm{CoV}-2$ ) has rapidly spread worldwide leading the WHO to declare the coronavirus disease outbreak as a public health emergency of international concern [4].

The clinical spectrum of the SARS-CoV-2 infection appear to be wide, encompassing asymptomatic infection, mild upper respiratory tract illness, and severe viral pneumonia with respiratory failure and death. Although COVID-19 cardinally manifests as diffuse alveolar damage, the involvement of other organ systems merits discussion. Recent literature suggests that the kidney is a vulnerable organ in COVID-19 patients with evidence of acute kidney injury (AKI) in up to $37.5 \%$ of fatal cases of COVID-19 [5]. Despite the recognition of AKI as a frequent complication of COVID-19, there is a lack of consensus data regarding its incidence and outcomes. This systematic literature review aims to bridge this knowledge gap and help establish widespread consensus using worldwide data.

\section{Methodology}

\section{Outcomes}

The primary outcome of this systematic literature review, conducted according to the preferred reporting items for systematic reviews and meta-analyses "PRISMA" checklist (Appendix 1), was with the objective to identify evidence regarding acute kidney involvement in COVID-19, focusing on the incidence and outcomes of COVID-19 patients with AKI.

\section{Database Sources and Search Strategy}

A systematic search was conducted in PubMed/MEDLINE and Cochrane Center Trials databases to identify all published literature relevant to AKI in COVID-19 patients from November 1, 2019 to June 5, 2020. Search terms such as "COVID," "Coronavirus," "Betacoronavirus," "kidney," "renal," and "creatinine" were included in the search criteria (Appendix 2). The search strategy was modified as per the search engine, as appropriate. Study identification was done in 2 phases: first, all the literature retrieved from the search strategy was imported into Rayyan QCRI via EndNote and reviewed using the inclusion and exclusion criteria. Second, the reference lists of the selected studies were reviewed to identify other relevant publications.

\section{Study Selection}

The inclusion criteria included prospective and retrospective cohort studies and case series assessing AKI in both adult and pediatric COVID-19 patients. All included studies needed to demonstrate laboratory-confirmed SARS-CoV-2 infection (including detection of SARS-CoV-2 nucleic acid via transcriptase polymerase chain reaction and CT scanning of the lung) and include demographic data, epidemiological data (incidence of AKI, severity, and comorbidities), laboratory and radiological data, treatment, and outcome. Case reports, systematic reviews, meta-analyses, randomized clinical trials, animal studies, and studies not in English were excluded. Studies exclusively on kidney transplant patients were also excluded from this analysis.

\section{Data Extraction}

The titles, abstracts, full-texts, and reference lists of the collected manuscripts were independently reviewed by 2 investigators (Z.M. and P.V.) to identify relevant studies for inclusion. Any disagreements or conflicts were resolved either via a consensus of the 2 reviewers or by the opinion of a third independent reviewer (R.C.). The schema for the selection of studies is shown in online suppl. Fig. 1; for all online suppl. material, see www.karger.com/ doi/10.1159/000514940. The data regarding patient demographics, presence of comorbidities, AKI incidence and severity, presence of hematuria and/or proteinuria, mortality rates, need for kidney replacement therapy (KRT), and outcomes were recorded electronically.

\section{Statistical Methods}

The outcomes included the incidence of AKI among COVID-19 patients, the proportion of COVID-19 patients with AKI receiving KRT over the study period, and mortality among COVID-19 patients with incident AKI. These outcomes and their $95 \%$ confidence intervals ( $95 \% \mathrm{CI}$ ) were calculated for each study. A meta-analysis of these outcomes was conducted. The degree of between-study heterogeneity was assessed using the $I^{2}$ test, where $I^{2} \geq 50 \%$ indicated high heterogeneity. Overall (pooled) estimates were calculated with random effects models for high heterogeneity and fixed effects models for low heterogeneity. Forest plots were used to visualize these outcomes in each study and the combined estimated outcomes with their 95\% CI. Publication bias was assessed graphically using funnel plots. To determine the source of heterogeneity, sensitivity analyses and random-effects meta-regression were performed based on these parameters (criteria used for defining AKI, the study design, the geographic location of the study, age of the studied population, and the sample size of the study). A $p$-value $\leq 0.05$ was considered for statistical significance. All statistical analyses were performed with $\mathrm{R}$ software version 3.1.0.

\section{Results}

\section{Study Selection and Details}

The initial database search yielded 146 potential articles and considered 31 additional studies by searching through citation lists and unpublished manuscripts (online suppl. Fig. 1). A total of 177 studies were screened, of which 113 were excluded. After screening titles and abstracts, 61 full-text articles were obtained for detailed evaluation based on the inclusion criteria. One study was excluded after the full-text review, yielding a total of 60

Fig. 1. AKI incidence among COVID positive patients. a Forest plot of the meta-analysis different studies. The lower diamond in the graph represents the pooled estimate. b Funnel plot for AKI incidence among COVID positive patients. AKI, acute kidney injury.

(For figure see next page.) 
Aggarwal, S et al., 2020

Arentz, M et al., 2020

Argenzlano, MG et al., 2020

Cao, W et al., 2020

Chan, L et al., 2020

Chen, $\mathrm{N}$ et al., 2020

Chen, T et al., 2020a

Chen, $T$ et al., 2020b

Cheng, Y et al., 2020

Cummmings, MJ et al., 2020

Daging, $\mathrm{H}$ et al., 2020

Deng, $Y$ et al., 2020

Derespina, K et al., 2020

Diao, B et al., 2020

Du, $Y$ et al., 2020

Dudolgnan, E et al., 2020

Fisher, $\mathrm{M}$ et al., 2020

Guan, W et al., 2020

Gupte, S et al., 2020

Gugin, Z et al., 2020

Hong, KS et al., 2020

Huang, C et al., 2020

Jamie, $\mathrm{H}$ et al., 2020

Jiahao, $Z$ et al., 2020

Li, $X$ et al., 2020

Ling, $\mathrm{H}$ et al., 2020

Luo, $X$ et al., 2020

Muner, $M$ et al., 2020

$\mathrm{Na}, \mathrm{KR}$ et al., 2020

Pel, G et al., 2020

Pelayo, J et al., 2020

Qjao, S et al., 2020

Qjngxian, C et al., 2020

Richardson, S et al., 2020

Ruan, Q et al., 2020

Ruben, $S$ et al., 2020

$\mathrm{Su}, \mathrm{H}$ et al., 2020

Wang, D et al., 2020a

Wang, D et al., 2020b

Wang, L et al., 2020

$\mathrm{Wu}, \mathrm{C}$ et al., 2020

Xiao, $\mathrm{G}$ et al., 2020

Xin-Ying, $Z$ et al., 2020

$X u, J$ et al., 2020

$X u, S$ et al., 2020

Xu, Y et al, 2020

Yang, $\mathrm{F}$ et al., 2020

Yang, $X$ et al., 2020

$Y i, Z$ et al., 2020

Yu, Y et al., 2020

Zhang, B et al., 2020

Zhen, Li et al., 2020

Zhou, F et al., 2020

Total (random effects)
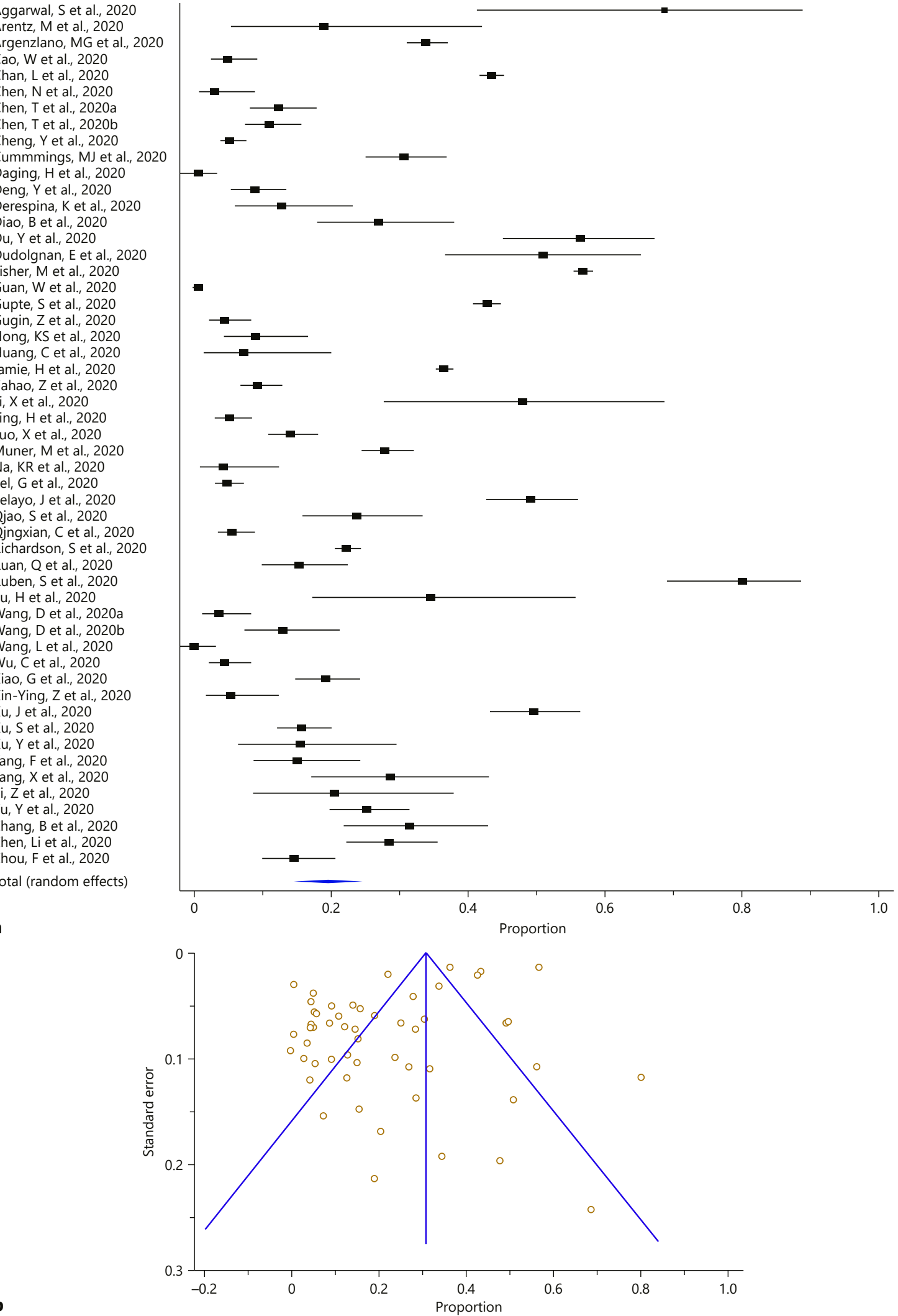
Argenzlano, MG et al., 2020

Chen, $\mathrm{N}$ et al., 2020

Chen, $T$ et al., 2020b

Cummmings, MJ et al., 2020

Derespina, K et al., 2020

$\mathrm{Du}, \mathrm{Y}$ et al., 2020

Dudolgnan, E et al., 2020

Fisher, $\mathrm{M}$ et al., 2020

Guan, W et al., 2020

Gupte, S et al., 2020

Gugin, Z et al., 2020

Hong, KS et al., 2020

Huang, $C$ et al., 2020

ICNARC et al., 2020

Jamie, $\mathrm{H}$ et al., 2020

Lim, JH et al., 2020

Ling, $\mathrm{H}$ et al., 2020

Ling, L et al., 2020

Pelayo, J et al., 2020

Qjao, $S$ et al., 2020

Richardson, $S$ et al., 2020

Ruan, Q et al., 2020

Ruben, $S$ et al., 2020

$\mathrm{Su}, \mathrm{H}$ et al., 2020

Wang, $D$ et al., 2020a

$X$ in-Ying, $Z$ et al., 2020

$X u$, J et al., 2020

$\mathrm{Xu}, \mathrm{Y}$ et al., 2020

Yang, $X$ et al., 2020

$Y i, Z$ et al., 2020

Yu, Y et al., 2020

Zhen, Li et al., 2020

Zhou, F et al., 2020

Total (random effects)

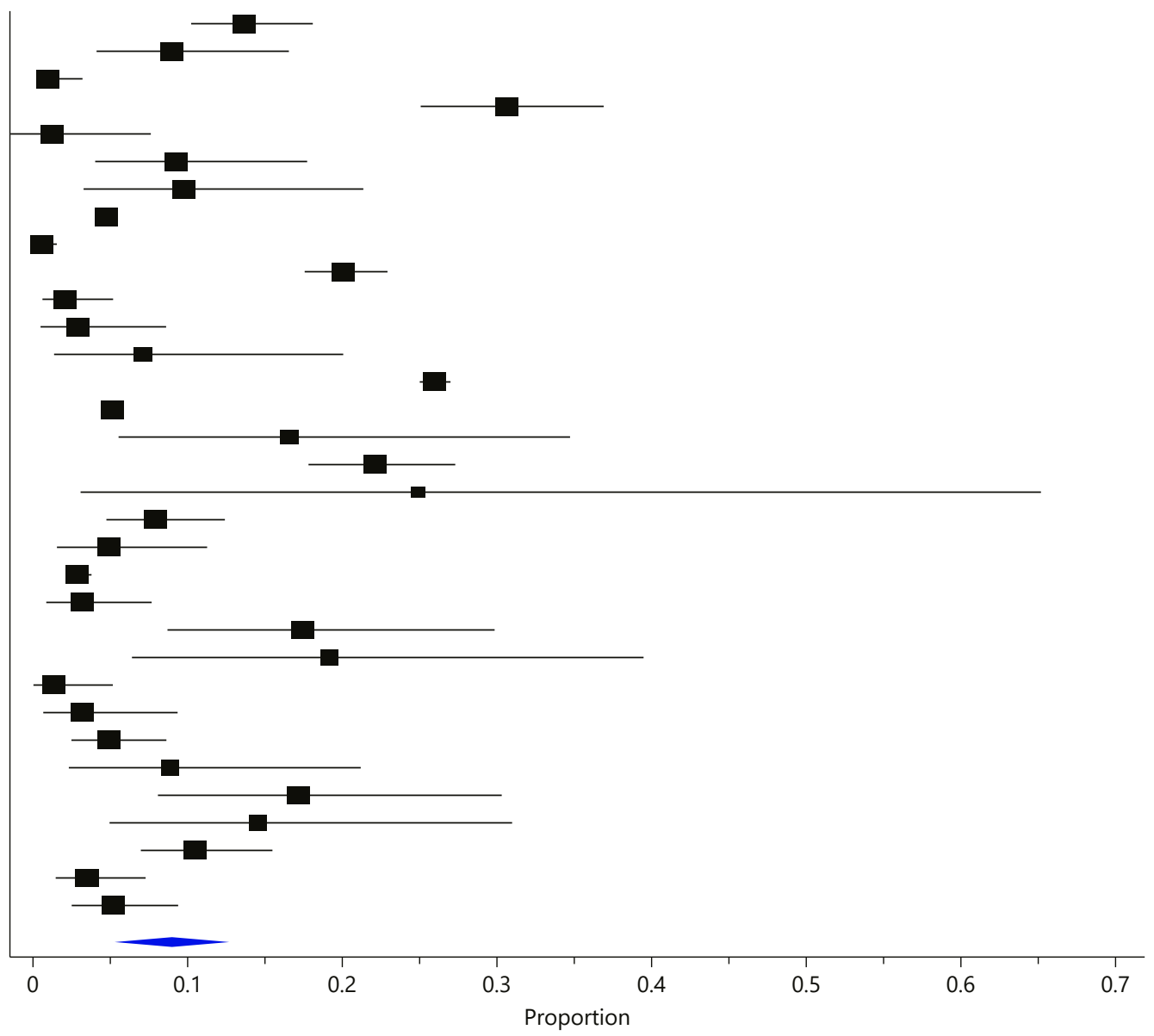

a

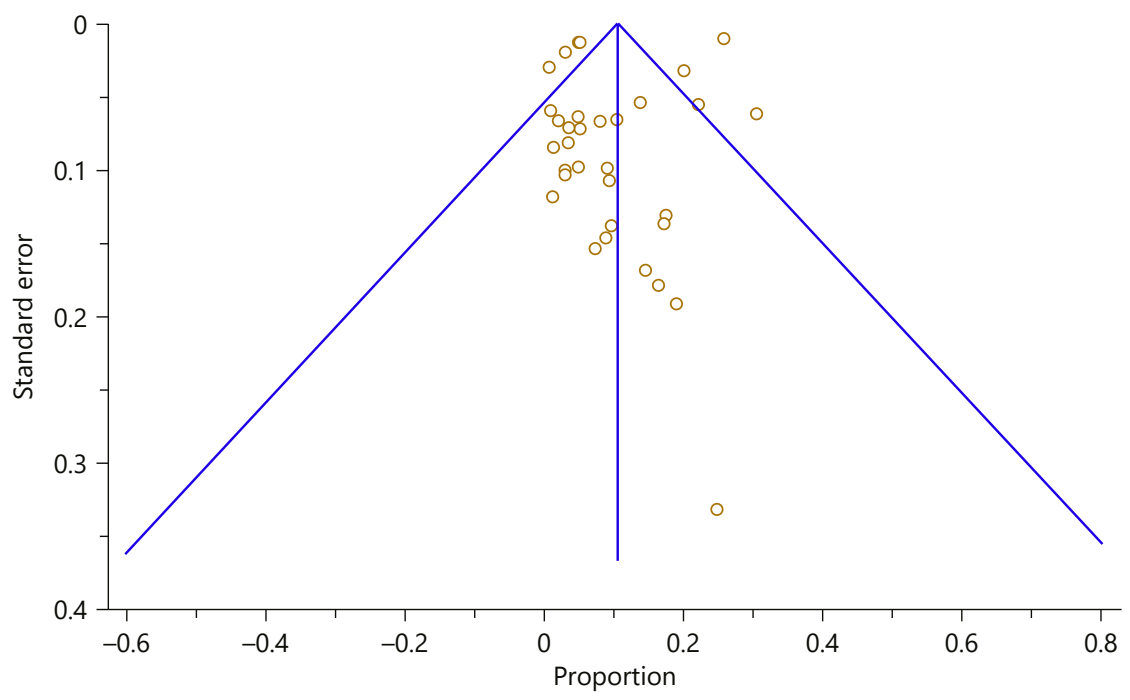

b

Fig. 2. Incidence of KRT in COVID positive patients. a Forest plot of the meta-analysis across different studies. The lower diamond in the graph represents the pooled estimate. b Funnel plot for KRT incidence among COVID positive patients. KRT, kidney replacement therapy. 
studies reporting the outcomes of interest. Of these, 40 were retrospective studies, 12 were prospective, and 8 were case series. Most of the studies $(n=40)$ were conducted in China, followed by 14 studies in USA, 3 in Korea, 2 in France, and 1 in UK.

The overall sample size of COVID-19 patients evaluated was 42,612 . The pooled median age of these patients was 61.1 years (median of $45.6-73$ years) and $60.9 \%(n=$ $25,936)$ were men. Pediatric patients were included in only one study ( $<2 \%$ of overall sample size). The most common comorbidities reported among these patients were hypertension $(28.4 \%[n=12,112])$, diabetes mellitus $(20.8 \%[n=8,844])$, obesity $(17.8 \%[n=7,590])$, chronic kidney disease $(5.2 \%[n=2,237])$, coronary artery disease $(3.5 \%[n=1,481])$, malignancy $(2.8 \%[n=$ $1,190])$, asthma $(2.5 \%[n=1,082]), \mathrm{CHF}(2.4 \%[n=$ $1,040])$, and COPD $(2.1 \%$ [ $n=914])$. The majority of the studies $(n=29)$ had used KDIGO AKI guidelines, followed by elevated serum creatinine level in 2 studies, elevated blood urea nitrogen or creatinine in 2 , elevated creatinine/uric acid in 1, and AKIN in 1, while 25 studies did not specify the criteria. Details of the studies are given in online suppl. Table 1 [5-64].

\section{Data Analysis}

Incidence of AKI among COVID-19 Patients

The pooled $(95 \% \mathrm{CI})$ incidence of AKI among COVID+ patients was $19.45 \%$ (95\% CI: $14.63-24.77 \%)\left(I^{2}=\right.$ 99.10\% [99.01-99.18\%]; $p<0.0001$; random effects; 53 studies; $n=29,142$ ) (online suppl. Table 2; Fig. 1).

\section{Proportion of COVID-19 Patients Requiring KRT}

Only 4 studies reported the data on AKI COVID patients receiving KRT. The pooled proportion (95\% CI) of AKI COVID+ patients receiving KRT was 39.04\% (16.3864.57\%) $\left(I^{2}=96.75 \%\right.$ [94.12-98.20\%]; $p<0.001$; random effects; 4 studies; $n=1,608$ ) (online suppl. Table 3 ). As expected, the pooled proportion (95\% CI) of COVID+ patients receiving KRT was much lower at $8.83 \%$ (5.64$12.66 \%)\left(I^{2}=98.85 \%\right.$ [98.69-99.00\%]; $p<0.0001$; random effects; 33 studies; $n=27,996$ ) (online suppl. Table 4; Fig. 2).

\section{Mortality among COVID-19 Patients with AKI}

The pooled proportion (95\% CI) of mortality among AKI COVID+ patients was 54.24\% (95\% CI: 44.70-63.63\%) $\left(I^{2}=97.53 \%\right.$ [96.74-98.12\%]; $p<0.001 ;$ random effects; 13 studies; $n=6,302$ ) (online suppl. Table 5; Fig. 3 ). While the pooled proportion $(95 \% \mathrm{CI})$ of mortality among COVID+ patients was $19.35 \%$ (95\% CI: $12.40-27.42 \%)\left(I^{2}=99.11 \%\right.$
[98.97-99.22\%]; $p<0.0001 ;$ random effects; 25 studies; $n=$ 17,470) (online suppl. Table 6; Fig. 4). Moreover, AKI COVID+ patients $(n=1,369)$ had significantly higher odds of mortality as compared with non-AKI COVID+ patients $(n=3,932)$ (pooled odds ratio: 18.63 [95\% CI: 15.67-22.15] $\left[I^{2}=0.00 \%(0.00-67.78 \%) ; p=0.6571\right.$; fixed effects; 5 studies) (online suppl. Table 7; Fig. 5). Visual inspection of the funnel plot showed an asymmetrical distribution, which indicated the presence of publication bias for all the above outcome measures (Fig. 1-5).

\section{Proteinuria and Hematuria}

The pooled proportion $(95 \% \mathrm{CI})$ of proteinuria among COVID+ patients was 52.47\% (95\% CI: 27.97-76.34\%) $\left(I^{2}=99.65 \%\right.$ [99.59-99.70\%]; $p<0.0001 ;$ random effects; 11 studies; $n=7,794)$. While the pooled proportion $(95 \%$ CI) of hematuria among COVID+ patients was 35.89\% (95\% CI: $25.94-46.50 \%)\left(I^{2}=95.55 \%\right.$ [93.14-97.11\%]; $p<0.0001$; random effects; 8 studies; $n=2,007)$.

\section{Sensitivity Analyses and Meta-regression}

The $I^{2}$ value for sensitivity analyses was like that obtained without excluding the studies based on the previously mentioned parameters (online suppl. Table 8). Also, the proportion (\%) of the outcomes obtained from the sensitivity analyses was within the $95 \%$ CI of the overall proportion for all the parameters (except for age and geography), indicating that the results of this metaanalysis are robust enough. To further explore the impact of these parameters on the outcomes, the meta-regression analyses were conducted (online suppl. Table 9). The meta-regression analyses reported that the pooled incidence of AKI among COVID+ patients was significantly higher among studies from geography other than China (OR: 2.34 [95\% CI: 1.50-3.64]), the prospective/retrospective study design (1.80 [1.07-3.02]), and studies with a mean/median age $\geq 60$ years $(3.87$ [2.53-5.91]), but significantly lower among studies with a sample size $\geq 175$ (0.62 [0.42-0.91]). Regarding mortality among COVID+ patients, higher mortality was observed in studies with a mean/median age $\geq 60$ years (3.94 [1.55-9.99]), the only significant parameter observed. None of the parameters were significantly associated with the incidence of KRT among COVID+ patients. These analyses were not conducted for other outcomes due to insufficient data. 


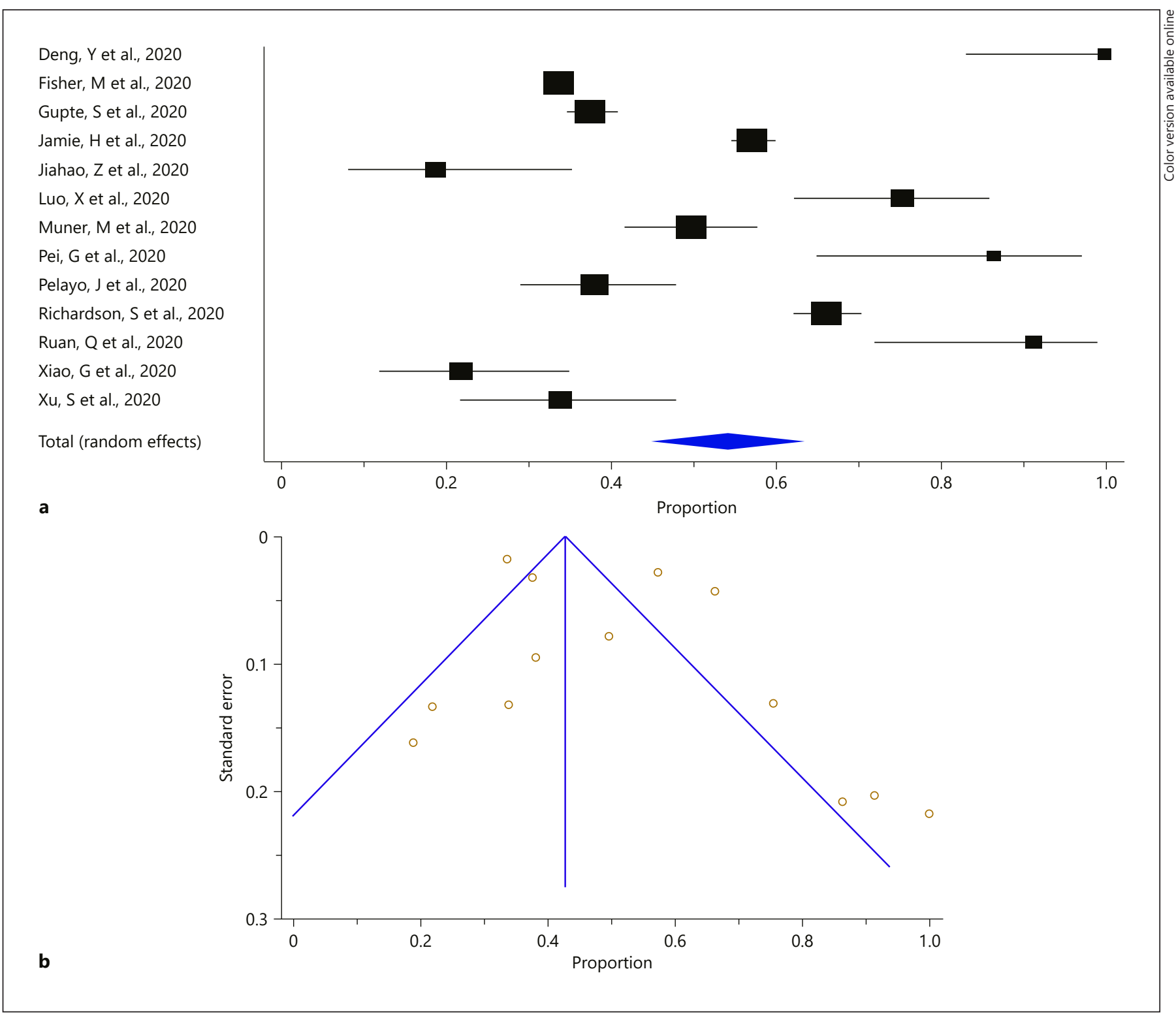

Fig. 3. Mortality among COVID positive patients with AKI. a Forest plot of the meta-analysis across different studies. The lower diamond in the graph represents the pooled estimate. b Funnel plot for mortality among overall COVID positive patients with AKI. AKI, acute kidney injury.

\section{Discussion}

COVID-19 primarily manifests as an acute respiratory illness with interstitial or alveolar pneumonia, but can also affect multiple organs, such as the kidneys, heart, liver, blood, and nervous system $[65,66]$. Recent literature suggests that kidneys are especially vulnerable in COVID-19 patients, with AKI being the most frequent manifestation [5]. There is a dearth of accurate consensus re- garding incidence, pathogenesis, diagnosis, management, and outcomes of AKI. This systematic literature review and meta-analysis specifically aims to address incidence and outcomes of AKI in COVID-19 patients. Our findings revealed that $\mathrm{AKI}$ was a frequently observed complication of COVID-19 infection, with a cumulative incidence of $19.76 \%$. COVID-19 patients had an overall mortality rate of $17.51 \%$. This is in line with the historical mortality estimates of the SERS and MERS epidemics (10 


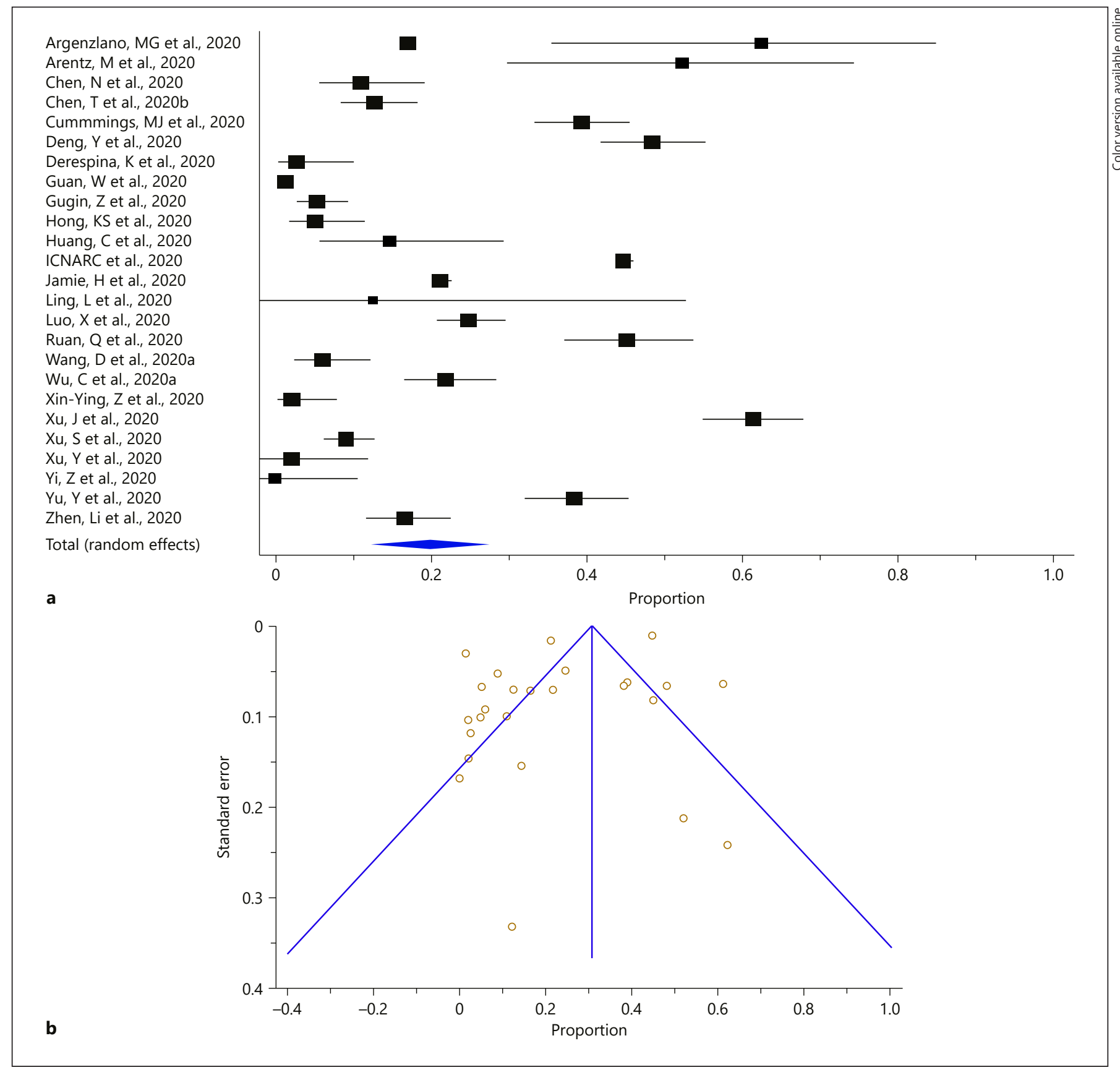

Fig. 4. Mortality among overall COVID positive patients. a Forest plot of the meta-analysis across different studies. The lower diamond in the graph represents the pooled estimate. b Funnel plot for mortality among overall COVID positive patients.

and $40 \%$, respectively) $[65,66]$. COVID-19 patients with AKI had a significantly higher mortality rate of $54.24 \%$ and, overall, 18 times higher risk of death when compared to COVID-19 patients without AKI. Thus, AKI is a major negative prognostic factor in COVID-19 patients with dire need of prevention and management in this susceptible population.

The pathophysiology of AKI in COVID-19 is complex, suggestive of a biphasic pattern with volume responsive AKI occurring in early stages of the disease and kidney 


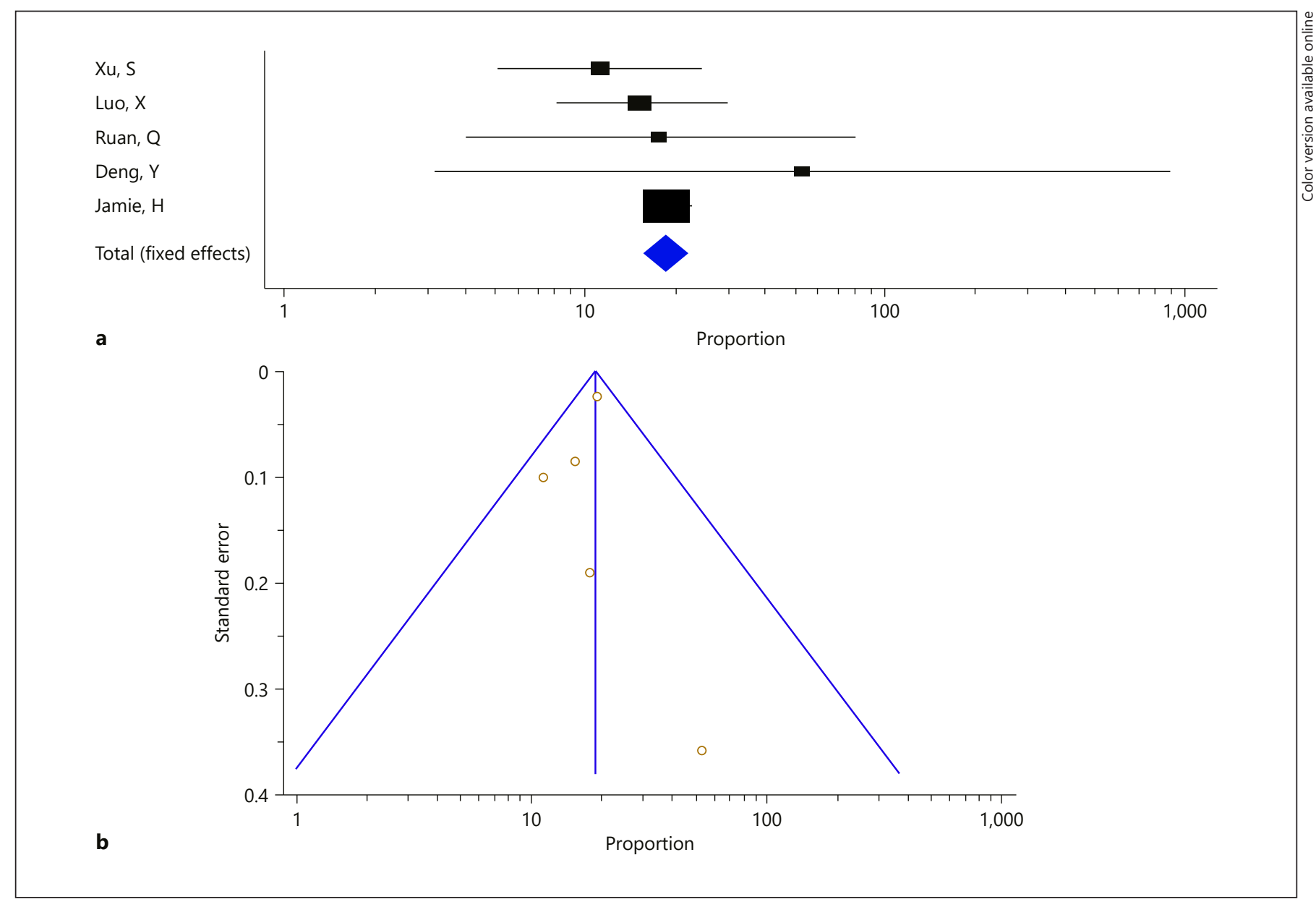

Fig. 5. Comparison of mortality among AKI versus Non-AKI COVID+ patients. a Forest plot of the meta-analysis of mortality among AKI versus non-AKI COVID+ patients across different studies. The lower diamond in the graph represents the pooled estimate. $\mathbf{b}$ Funnel plot of mortality among AKI versus non-AKI COVID+ patients across different studies. AKI, acute kidney injury.

injury occurring in later stages of the disease [67]. Acute lung injury that ensues in COVID-19 patients can effectuate impairment of the kidney function through its effect on gas exchange, release of pro-inflammatory mediators (IL-2, IL-7, IL-10, IFN- $\gamma$, IP10, GCSF, and MCP1), and cardiopulmonary interactions $[67,68]$. The lung-kidney crosstalk may be bidirectionally deleterious, due to a cascade of irreversible cytokine release [67, 69]. A transient febrile/illness-related proteinuria may also be seen, like the MERS CoV infection $[6,70]$. The cellular entry of SARS-CoV-2 is mediated by angiotensin-converting enzyme II, which is highly expressed in the podocytes and proximal tubules $(100 \times$ levels compared to the lungs $)$ and upregulated in patients with COVID-19 [7, 71-73]. An autopsy series conducted by Puelles et al. [74] $(n=27)$, showed that SARS-CoV-2 has organotropism beyond the pulmonary tract. Recent postmortem kidney pathology findings in patients with COVID-19 suggests that although there are little signs of viral nephropathy, noted acute tubular injury in the setting of creatinine elevation is reversible with appropriate care such as aggressive fluid management [75]. Mechanical ventilation may be provided to patients which affects the renal and systemic hemodynamics, stimulates sympathetic pathways, and causes biotrauma $[9,76]$. Recent studies in London indicate that COVID-19 may present as multisystem inflammatory syndrome; however, there is still limited information regarding this COVID-19 associated condition.

In terms of management of patients with COVID-19 and AKI, discussion of goals of supportive care (e.g., 
KRT) among clinicians and patients/families is recommended. Standard recommendations by KDIGO include nutritional and fluid support, avoidance of nephrotoxins, maintenance of oxygenation saturation, and hemodynamic stability for the management of AKI. KRT may reduce the burden of inflammatory mediators and cytokines as supported by a study with Ghani et al. [77-80] particularly to patients with AKI; however, more studies are required. Various modalities such as peritoneal dialysis, hemodialysis, CKRT, and sustained low-efficiency dialysis can be utilized for AKI management. Although CKRT is the preferred modality in most ICU settings, the choice of modality should be based on the hemodynamic status, patient characteristics and needs, available resources, and health-care expertise [81-83]. Newer modalities such as CytoSorb (an extracorporeal cytokine filter) and Oxiris (a blood purification device for cytokine clearance) have received expedited FDA approval for use in adult COVID-19 patients ( $\geq 18$ years old) with AKI $[84,85]$, where the provider can obtain an exploratory investigational new drug for use in the pediatric population. Evidence is actively evolving but insufficient for widespread application in COVID-19 patients with AKI.

\section{Limitations}

This systematic literature review is constrained due to the paucity of relevant peer reviewed studies and data. Our review excludes studies that are not in the English language. In several studies, baseline creatinine levels were unavailable and data of kidney recovery, drug exposure, or long-term kidney outcomes were not reported. Renal pathology data were sparse, and it was difficult to assess the precise etiology of AKI in COVID-19 patients. Additionally, visual inspection of the funnel plots for the incidence of AKI, need of KRT, and mortality showed an asymmetrical distribution, which indicates the possibility of publication bias (Fig. 2-5). The differences between this systematic review and recently published work helps address the prior lack of generalizability; this study includes data spanning Asia, Europe, and USA in addition to including a broader scope of studies as highlighted in online suppl. Table 10. Additionally, this systematic review reports higher incidence of AKI with COVID-19 patients (results $=19.76 \%$, range in literature $=2-11 \%$ ) and delves into a possible explanation with the results on the need for KRT [83, 86-95]. Future studies should assess risk stratification, specific management strategies, and long-term outcomes of COVID-19 patients with AKI.

\section{Conclusion}

AKI is increasingly being recognized as a negative prognostic factor in patients with COVID-19. Its high incidence $(19.76 \%)$ and mortality rate $(54.24 \%)$ mandated routine and standardized monitoring of the kidney function during hospitalization. Supportive measures, fluid management, and prevention of immune dysregulation are necessary to potentially improve outcomes in these patients. Effective use of KRT should be considered with evolving multiorgan failure, especially in patients with concomitant mechanical ventilation. Therapeutic options in COVID-19 patients with AKI require further exploration with randomized controlled trials. Improved awareness among health-care providers and proactive prevention and management of AKI are key to improve the high mortality observed in these patients.

\section{Statement of Ethics}

This review was conducted ethically in accordance with the World Medical Association Declaration of Helsinki.

\section{Conflict of Interest Statement}

J.A.N. has received consulting fees from Baxter Healthcare and Renibus Therapeutics.

\section{Funding Sources}

The authors did not receive any funding.

\section{Author Contributions}

R.R., Z.M., P.V., R.C., and J.N. contributed to the conception and design of the study. Z.M., P.V., K.M., A.T., and J.N. performed data and statistical analysis. All the authors wrote sections of the manuscript, contributed to manuscript revision, and read and approved the submitted version. 


\section{Appendix 1}

\section{Preferred reporting items for systematic reviews and meta-analyses checklist}

\begin{tabular}{|c|c|c|c|}
\hline Section and topic & No. & Checklist item & $\begin{array}{l}\text { Inclusion } \\
\text { (page \#) }\end{array}$ \\
\hline \multicolumn{4}{|l|}{ Title } \\
\hline Title & 1 & Identify the report as a systematic review and meta-analysis of individual participant data & 1 \\
\hline \multicolumn{4}{|l|}{ Abstract } \\
\hline Structured summary & 2 & $\begin{array}{l}\text { Provide a structured summary including, as applicable: background; objectives; data sources; study eligibility } \\
\text { criteria; participants and interventions; study appraisal and synthesis methods; results; limitations; } \\
\text { conclusions and implications of key findings; systematic review registration number }\end{array}$ & 1 \\
\hline \multicolumn{4}{|l|}{ Introduction } \\
\hline Rationale & 3 & Describe the rationale for the review in the context of what is already known & 1,2 \\
\hline Objectives & 4 & $\begin{array}{l}\text { Provide an explicit statement of questions being addressed with reference to participants, interventions, } \\
\text { comparisons, outcomes, and study design (PICOS) }\end{array}$ & 1,2 \\
\hline \multicolumn{4}{|l|}{ Methods } \\
\hline $\begin{array}{l}\text { Protocol and } \\
\text { registration }\end{array}$ & 5 & $\begin{array}{l}\text { Indicate if a review protocol exists, if and where it can be accessed (e.g., web address), and, if available, } \\
\text { provide registration information including registration number }\end{array}$ & N/A \\
\hline Eligibility criteria & 6 & $\begin{array}{l}\text { Specify study characteristics (e.g., PICOS, length of follow-up) and report characteristics (e.g., years } \\
\text { considered, language, publication status) used as criteria for eligibility, giving rationale }\end{array}$ & 2 \\
\hline Information sources & 7 & $\begin{array}{l}\text { Describe all information sources (e.g., databases with dates of coverage, contact with study authors to } \\
\text { identify additional studies) in the search and date last searched }\end{array}$ & 2 \\
\hline Search & 8 & $\begin{array}{l}\text { Present full electronic search strategy for at least one database, including any limits used, such that it could } \\
\text { be repeated }\end{array}$ & Appendix 2 \\
\hline Study selection & 9 & $\begin{array}{l}\text { State the process for selecting studies (i.e., screening, eligibility, included in systematic review, and, if } \\
\text { applicable, included in the meta-analysis) }\end{array}$ & 2 \\
\hline $\begin{array}{l}\text { Data collection } \\
\text { process }\end{array}$ & 10 & $\begin{array}{l}\text { Describe the method of data extraction from reports (e.g., piloted forms, independently, in duplicate) and } \\
\text { any processes for obtaining and confirming data from investigators }\end{array}$ & 2 \\
\hline Data items & 11 & $\begin{array}{l}\text { List and define all variables for which data were sought (e.g., PICOS, funding sources) and any assumptions } \\
\text { and simplifications made }\end{array}$ & 2 \\
\hline $\begin{array}{l}\text { Risk of bias in } \\
\text { individual studies }\end{array}$ & 12 & $\begin{array}{l}\text { Describe methods used for assessing risk of bias of individual studies (including specification of whether this } \\
\text { was done at the study or outcome level), and how this information is to be used in any data synthesis }\end{array}$ & $2-5$ \\
\hline Summary measures & 13 & State the principle summary measures (e.g., risk ratio, difference in means) & 2 \\
\hline Synthesis of results & 14 & $\begin{array}{l}\text { Describe the methods of handling data and combining results of studies, if done, including measures of } \\
\text { consistency }\left(\text { e.g., } I^{2}\right) \text { for each meta-analysis }\end{array}$ & 2 \\
\hline $\begin{array}{l}\text { Risk of bias across } \\
\text { studies }\end{array}$ & 15 & $\begin{array}{l}\text { Specify any assessment of risk of bias that may affect the cumulative evidence (e.g., publication bias, selective } \\
\text { reporting within studies) }\end{array}$ & $2-5$ \\
\hline Additional analyses & 16 & $\begin{array}{l}\text { Describe methods of additional analyses (e.g., sensitivity or subgroup analyses, meta-regression), if done, } \\
\text { indicating which were prespecified }\end{array}$ & N/A \\
\hline
\end{tabular}

\section{Results}

Study selection

17 Give numbers of studies screened, assessed for eligibility, and included in the review, with reasons for exclusions at each stage, ideally with a flow diagram

\begin{tabular}{|c|c|c|c|}
\hline Study characteristics & 18 & $\begin{array}{l}\text { For each study, present characteristics for which data were extracted (e.g., study size, PICOS, and follow-up } \\
\text { period) and provide the citations }\end{array}$ & $2-5$ \\
\hline $\begin{array}{l}\text { Risk of bias within } \\
\text { studies }\end{array}$ & 19 & Present data on risk of bias of each study and, if available, any outcome-level assessment (see item 12) & $2-5$ \\
\hline $\begin{array}{l}\text { Results of individual } \\
\text { studies }\end{array}$ & 20 & $\begin{array}{l}\text { For all outcomes considered (benefits or harms), present, for each study: (a) simple summary data for each } \\
\text { intervention group and (b) effect estimates and confidence intervals, ideally with a forest plot }\end{array}$ & $2-5$ \\
\hline Synthesis of results & 21 & Present results of each meta-analysis done, including confidence intervals and measures of consistency & $2-5$ \\
\hline
\end{tabular}




\begin{tabular}{|c|c|c|c|}
\hline Section and topic & No. & Checklist item & $\begin{array}{l}\text { Inclusion } \\
\text { (page \#) }\end{array}$ \\
\hline $\begin{array}{l}\text { Risk of bias across } \\
\text { studies }\end{array}$ & 22 & Present results of any assessment of risk of bias across studies (see item 15) & $2-5$ \\
\hline Additional analysis & 23 & $\begin{array}{l}\text { Give results of additional analyses, if done (e.g., sensitivity or subgroup analyses, meta-regression [see item } \\
\text { 16]) }\end{array}$ & $\mathrm{N} / \mathrm{A}$ \\
\hline \multicolumn{4}{|l|}{ Discussion } \\
\hline Summary of evidence & 24 & $\begin{array}{l}\text { Summarize the main findings including the strength of evidence for each main outcome; consider their } \\
\text { relevance to key groups (e.g., health-care providers, users, and policy makers) }\end{array}$ & $5-9$ \\
\hline Limitations & 25 & $\begin{array}{l}\text { Discuss limitations at the study and outcome level (e.g., risk of bias), and review level (e.g., incomplete } \\
\text { retrieval of identified research, reporting bias) }\end{array}$ & 9 \\
\hline Conclusions & 26 & $\begin{array}{l}\text { Provide a general interpretation of the results in the context of other evidence, and implications for future } \\
\text { research }\end{array}$ & 9 \\
\hline \multicolumn{4}{|l|}{ Funding } \\
\hline Funding & 27 & $\begin{array}{l}\text { Describe sources of funding for the systematic review and other support (e.g., supply of data); role of funders } \\
\text { for the systematic review }\end{array}$ & 9 \\
\hline
\end{tabular}

\section{Appendix 2}

Database search strategy

\begin{tabular}{ll}
\hline Database & MEDLINE/PubMed \\
\hline Date & 05/19/2020 \\
\hline Strategy & 1. Covid* OR Coronavirus OR Betacoronavirus \\
& 2. Kidney OR Renal OR Creatinine \\
& 3. “2019/11/01”[Date - Entry]: "2020/07/28”[Date - Entry] \\
& 4. \#1 AND \#2 AND \#3 \\
& 5. \#4 Filters: humans, English \\
\hline
\end{tabular}

\section{References}

1 Sohrabi C, Alsafi Z, O’Neill N, Khan M, Kerwan A, Al-Jabir A, et al. World Health Organization declares global emergency: a review of the 2019 novel coronavirus (COVID-19). Int J Surg. 2020;76:71-6.

2 Shanmugaraj B, Malla A, Phoolcharoen W. Emergence of novel coronavirus 2019-nCoV: need for rapid vaccine and biologics development. Pathogens. 2020;9(2):148.

3 Rothan HA, Byrareddy SN. The epidemiology and pathogenesis of coronavirus disease (COVID-19) outbreak. J Autoimmun. 2020;109: 102433.

4 WHO (World Health Organization). Statement on the meeting of the International Health Regulations (2005) Emergency Committee regarding the outbreak of novel coronavirus (2019-nCoV). Geneva, Switzerland: WHO Newsl; 2020.
5 Huang C, Wang Y, Li X, Ren L, Zhao J, Hu Y, et al. Clinical features of patients infected with 2019 novel coronavirus in Wuhan, China. Lancet. 2020;395(10223):497-506.

6 Pei G, Zhang Z, Peng J, Liu L, Zhang C, Yu C, et al. Renal involvement and early prognosis in patients with COVID-19 pneumonia. J Am Soc Nephrol. 2020;31(6):1157-65.

7 Su H, Yang M, Wan C, Yi LX, Tang F, Zhu HY, et al. Renal histopathological analysis of 26 postmortem findings of patients with COVID-19 in China. Kidney Int. 2020;98(1):219-27.

8 Diao B, Wang C, Wang R, Feng Z, Tan Y, Wang $\mathrm{H}$, et al. Human kidney is a target for novel severe acute respiratory syndrome coronavirus 2 (SARS-CoV-2) infection. medRxiv.2020. doi: 10.1101/2020.03.04.20031120.
9 Cheng Y, Luo R, Wang K, Zhang M, Wang Z, Dong $\mathrm{L}$, et al. Kidney disease is associated with in-hospital death of patients with COVID-19. Kidney Int. 2020;97(5):829-38.

10 Aggarwal S, Garcia-Telles N, Aggarwal G, Lavie C, Lippi G, Henry BM. Clinical features, laboratory characteristics, and outcomes of patients hospitalized with coronavirus disease 2019 (COVID-19): early report from the United States. Diagnosis. 2020; 7(2):91-6.

11 Chen T, Dai Z, Mo P, Li X, Ma Z, Song S, et al. Clinical characteristics and outcomes of older patients with coronavirus disease 2019 (COVID-19) in Wuhan, China (2019): a single-centered, retrospective. J GerontolABiol Sci Med Sci. 2020;75(9):1788-95. 
12 Li X, Wang L, Yan S, Yang F, Xiang L, Zhu J, et al. Clinical characteristics of 25 death cases with COVID-19: a retrospective review of medical records in a single medical center, Wuhan, China. Int J Infect Dis. 2020;94:128-32.

13 Ling L, So C, Shum HP, Chang PKS, Lai CKC, Kandamby DH, et al. Critically ill patients with COVID-19 in Hong Kong: a multicentre retrospective observational cohort study. Crit Care Resusc. 2020;22(2):119-25.

14 Richardson S, Hirsch JS, Narasimhan M, Crawford JM, McGinn T, Davidson KW, et al. Presenting characteristics, comorbidities, and outcomes among 5700 patients hospitalized with COVID-19 in the New York City area. JAMA. 2020;323(20):2052-9.

15 Wang L, Li X, Chen H, Yan S, Li D, Li Y, et al. Coronavirus disease 19 infection does not result in acute kidney injury: an analysis of 116 hospitalized patients from Wuhan, China. Am J Nephrol. 2020;51(5):343-8.

16 Yang F, Shi S, Zhu J, Shi J, Dai K, Chen X. Analysis of 92 deceased patients with COVID-19. J Med Virol. 2020;92(11):2511-5.

17 Wang D, Yin Y, Hu C, Liu X, Zhang X, Zhou S, et al. Clinical course, and outcome of 107 patients infected with the novel coronavirus, SARS-CoV-2, discharged from two hospitals in Wuhan, China. Crit Care. 2020;24(1): 188.

18 Yang X, Yu Y, Xu J, Shu H, Xia J, Liu H, et al. Clinical course and outcomes of critically ill patients with SARS-CoV-2 pneumonia in Wuhan, China: a single-centered, retrospective, observational study. Lancet Respir Med. 2020;8(5):475-81.

19 Chen N, Zhou M, Dong X, Qu J, Gong F, Han $\mathrm{Y}$, et al. Epidemiological and clinical characteristics of 99 cases of 2019 novel coronavirus pneumonia in Wuhan, China: a descriptive study. Lancet. 2020;395(10223):507-13.

20 Zhou F, Yu T, Du R, Fan G, Liu Y, Liu Z, et al. Clinical course and risk factors for mortality of adult inpatients with COVID-19 in Wuhan, China: a retrospective cohort study. Lancet. 2020;395(10229): 1054-62.

21 Wang D, Hu B, Hu C, Zhu F, Liu X, Zhang J, et al. Clinical characteristics of 138 hospitalized patients with 2019 novel coronavirus-infected pneumonia in Wuhan, China. JAMA. 2020;323(11):1061-9.

22 Zhang G, Hu C, Luo L, Fang F, Chen Y, Li J, et al. Clinical features and short-term outcomes of 221 patients with COVID-19 in Wuhan, China. J Clin Virol. 2020;127:104364.

23 Xiao G, Hu H, Wu F, Sha T, Huang A, Li H, et al. Acute kidney injury in patients hospitalized with COVID-19 in Wuhan, China: a singlecenter retrospective observational study. medRxiv. 2020. doi: 10.1101/2020.04.06.20055194.

24 Guan W, Ni Z, Hu Y, Liang W, Ou C, He J, et al. Clinical characteristics of coronavirus disease 2019 in China. N Engl J Med. 2020; $382(18): 1708-20$
25 Arentz M, Yim E, Klaff L, Lokhandwala S, Riedo FX, Chong M, et al. Characteristics and outcomes of 21 critically Ill patients with COVID-19 in Washington State. JAMA. 2020; 323(16):1612-4.

26 Zhao XY, Xu XX, Yin HS, Hu QM, Xiong T, Tang YY, et al. Clinical characteristics of patients with 2019 coronavirus disease in a nonWuhan area of Hubei Province, China: a retrospective study. BMC Infect Dis. 2020;20(1): 311.

27 Anti-2019-nCoV Volunteers; Li Z, Wu M, Yao J, Guo J, Liao X, et al. Caution on kidney dysfunctions of COVID-19 patients. medRxiv.2020.doi: 10.1101/2020.02.08.20021212.

28 ICNARC. ICNARC report on COVID-19 in critical care. ICNARC COVID-19 study case mix program database; 2020 .

29 Cummings MJ, Baldwin MR, Abrams D, Jacobson SD, Meyer BJ, Balough EM, et al. Epidemiology, clinical course, and outcomes of critically ill adults with COVID-19 in New York City: a prospective cohort study. Lancet. 2020;395(10239):1763-70.

30 Zheng Y, Sun LJ, Xu M, Pan J, Zhang YT, Fang $\mathrm{XL}$, et al. Clinical characteristics of $34 \mathrm{COV}$ ID-19 patients admitted to intensive care unit in Hangzhou, China. J Zhejiang Univ Sci B. 2020;21(5):378-87.

31 Yuan H, Lu X, Guo E, Hu F, Gao Z. Clinical features of acute kidney injury in coronavirus disease 2019: a case report with review of literature. 2020

32 Argenziano MG, Bruc SL, Slate CL, Slater CL, Tiao JR, Baldwin MR, et al. Characterization and clinical course of 1000 patients with coronavirus disease 2019 in New York: retrospective case series. BMJ. 2020;369:m1996.

33 Liu R, Ma Q, Han H, Su H, Liu F, Wu K, et al. The value of urine biochemical parameters in the prediction of the severity of coronavirus disease 2019. Clin Chem Lab Med. 2020; 58(7):1121-4

34 Cao M, Zhang D, Wang Y, Lu Y, Zhu X, Li Y, et al. Clinical features of patients infected with the 2019 novel coronavirus (COVID-19) in Shanghai, China. medRxiv. 2020. doi: 10.1101/2020.03.04.20030395.

$35 \mathrm{Xu}$ S, Fu L, Fei J, Xiang HX, Xiang Y, Tan ZX, et al. Acute kidney injury at early stage as a negative prognostic indicator of patients with COVID-19: a hospital-based retrospective analysis. medRxiv. 2020. doi: 10.1101/2020. 03.24.20042408.

36 Cai Q, Huang D, Ou P, Yu H, Zhu Z, Xia Z, et al. COVID-19 in a designated infectious diseases hospital outside Hubei Province, China. Allergy Eur J Allergy Clin Immunol. 2020; 75(7):1742-52.

37 Xu Y, Xu Z, Liu X, Cai L, Zheng H, Huang Y, et al. Clinical findings in critical ill patients infected with SARS-Cov-2 in Guangdong Province, China: a multi-center, retrospective, observational study. medRxiv. 2020. doi: $10.1101 / 2020.03 .03 .20030668$
38 Shi Q, Zhao K, Yu J, Jiang F, Feng J, Zhao K et al. Clinical characteristics of $101 \mathrm{COV}$ ID-19 nonsurvivors in Wuhan, China: a retrospective study. medRxiv. 2020. doi: 10.1101/2020.03.04.20031039.

39 Luo X, Xia H, Yang W, Wang B, Guo T, Xiong J, et al. Characteristics of patients with COVID-19 during epidemic ongoing outbreak in Wuhan, China. medRxiv. 2020. doi: 10.1101/ 2020.03.19.20033175.

40 Ruan Q, Yang K, Wang W, Jiang L, Song J. Clinical predictors of mortality due to COVID-19 based on an analysis of data of $150 \mathrm{pa}-$ tients from Wuhan, China. Intensive Care Med. 2020;46(5):846-8.

$41 \mathrm{Hu}$ L, Chen S, Fu Y, Gao Z, Long H, Ren HW, et al. Risk factors associated with clinical outcomes in 323 COVID-19 hospitalized patients in Wuhan, China. Clin Infect Dis. 2020; 71(16):2089-8.

42 Du Y, Tu L, Zhu P, Mu M, Wang R, Yang P, et al. Clinical features of 85 fatal cases of $\mathrm{CO}$ VID-19 from Wuhan: a retrospective observational study. Am J Respir Crit Care Med. 2020;201(11):1372-9.

43 Wu C, Chen X, Cai Y, Xi J, Zhou X, Xu S, et al. Risk factors associated with acute respiratory distress syndrome and death in patients with coronavirus disease 2019 pneumonia in Wuhan, China. JAMA Intern Med. 2020; 180(7):934-43.

44 Hong KS, Lee KH, Chung JH, Shin KC, Choi $\mathrm{EY}$, Jin HJ, et al. Clinical features and outcomes of 98 patients hospitalized with sarscov-2 infection in daegu, south korea: a brief descriptive study. Yonsei Med J. 2020;61(5): 431-7.

45 Deng Y, Liu W, Liu K, Fang YY, Shang J, Zhou $\mathrm{L}$, et al. Clinical characteristics of fatal and recovered cases of coronavirus disease 2019 in Wuhan, China: a retrospective study. Chin Med J. 2020;133(11):1261-7.

46 Hirsch JS, Ng JH, Ross DW, Sharma P, Shah $\mathrm{HH}$, Barnett RL, et al. Acute kidney injury in patients hospitalized with COVID-19. Kidney Int. 2020;98(1):209-18.

47 Mohamed MM, Lukitsch I, Torres-Ortiz AE, Walker JB, Varghese V, Hernandez-Arroyo $\mathrm{CF}$, et al. Acute kidney injury associated with coronavirus disease 2019 in Urban New Orleans. Kidney360. 2020;1(7):614-22.

48 Chan L, Chaudhary K, Saha A, Chauhan K, Vaid A, Baweja M, et al. Acute kidney injury in hospitalized patients with COVID-19. medRxiv. 2020. doi: 10.1101/2020.05.04.20090944.

49 Fisher M, Neugarten J, Bellin E, Yunes M, Stahl L, Johns TS, et al. AKI in hospitalized patients with and without COVID-19: a comparison study. J Am Soc Nephrol. 2020;31(9):2145-57. doi: 10.1681/ASN.2020040509.

50 Lim J-H, Park S-H, Jeon Y, Cho JH, Jung HY, Choi JY, et al. Fatal outcomes of COVID-19 in patients with severe acute kidney injury. J Clin Med. 2020;9(6):1718. doi: 10.3390/ jcm9061718. 
$51 \mathrm{Wu} \mathrm{H}$, Larsen CP, Hernandez-Arroyo CF, Mohamed MMB, Caza T, Sharshir M, et al. AKI and collapsing glomerulopathy associated with COVID-19 and APOL 1 high-risk genotype.JAm SocNephrol.2020;31(8):168895. doi: 10.1681/ASN.2020050558.

52 Pelayo J, Lo KB, Bhargav R, Gul F, Peterson E, DeJoy R III, et al. Clinical characteristics and outcomes of community- and hospital-acquired acute kidney injury with COVID-19 in a US inner city hospital system. CardioRenal Med. 2020;10:223-31. doi: 10.1159/000509182.

53 Nalesso F, Garzotto F, Cattarin L, Gobbi L, Qassim L, Sgarabotto L, et al. A continuous renal replacement therapy protocol for patients with acute kidney injury in intensive care unit with COVID-19. J Clin Med. 2020;9(5):1529. doi: 10.3390/jcm9051529.

54 Zhang J, Li J, Su L, Yang J, Jiang X, Jiang N, et al. [Clinical characteristics and risk factors of acute kidney injury in coronavirus disease 2019]. Zhonghua Wei Zhong Bing Ji Jiu Yi Xue. 2020;32(4):407-11. doi: 10.3760/cma.j. cn121430-20200302-00198.

$55 \mathrm{Xu}$ J, Yang X, Yang L, Zou X, Wang Y, Wu Y, et al. Clinical course and predictors of 60-day mortality in 239 critically ill patients with COVID-19: a multicenter retrospective study from Wuhan,China.CritCare.2020;24(1):394. doi: 10.1186/s13054-020-03098-9.

$56 \mathrm{Na}$ KR, Kim HR, Ham Y, Choi DE, Lee KW, Moon JY, et al. Acute kidney injury and kidney damage in COVID-19 patients. J Korean Med Sci. 2020;35(28):e257. doi: 10.3346/ jkms.2020.35.e257.

57 Dudoignon E, Moreno N, Deniau B, Coutrot $\mathrm{M}$, Longer R, Amiot Q, et al. Activation of the reninangiotensin-aldosterone system is associated with acute kidney injury in COVID-19. Anaesth Crit Care Pain Med. 2020;39(4):4535. doi: 10.1016/j.accpm.2020.06.006.

58 Ruben S, Orieux A, Prevel R, Garric A, Bats $\mathrm{ML}$, Dabernat $S$, et al. Characterisation of acute kidney injury in critically Ill patients with severe coronavirus disease-2019 (COVID-19). medRxiv. 2020. doi: 10.1101/2020.05. 06.20069872 .

59 Chen T, Wu D, Chen H, Yan W, Yang D, Chen G, et al. Clinical characteristics of 113 deceased patients with coronavirus disease 2019: retrospective study. BMJ. 2020; 368:m1091. doi: 10.1136/bmj.m1091.

60 Derespina K, Kaushik S, Plichta A, Conway EE, Bercow A, Choi J, et al. Clinical manifestations and outcomes of critically Ill children and adolescents with COVID-19 in New York City. J Pediatr. 2020;226:55-63.e2. doi: 10. 1016/j.jpeds.2020.07.039

61 Gupta S, Hayek SS, Wang W, Chan L, Mathews KS, Melamed ML, et al. Factors associated with death in critically Ill patients with coronavirus disease 2019 in the US. JAMA Intern Med. 2020;180(11):1436-47. doi: 10.1001/jamainternmed.2020.3596.
62 Zhang B, Zhou X, Qiu Y, Feng F, Feng J, Jia Y, et al. Clinical characteristics of 82 death cases with COVID-19. MedRxiv. 2020. doi: 10.1101/2020.02.26.20028191.

63 Hong D, Long L, Wang AY, Lei Y, Tang Y, Zhao JW, et al. Kidney manifestations of mild, moderate and severe coronavirus disease 2019: a retrospective cohort study. Clin Kidney J. 2020;13(3):340-6. doi: 10.1093/ckj/ sfaa083.

64 Zhou H, Zhang Z, Fan H, Li J, Li M, Dong Y, et al. Urinalysis, but not blood biochemistry, detects the early renal-impairment in patients with COVID-19. MedRxiv. 2020. doi: 10.1101/2020.04.03.20051722.

65 WHO (World Health Organization). Summary of probable SARS cases with onset of illness from 1 November 2002 to 31 July 2003 [online]. 2004.

66 Memish ZA, Perlman S, Van Kerkhove MD, Zumla A. Middle East respiratory syndrome. Lancet. 2020;395(10229):1063-77.

67 Basu RK, Wheeler DS. Kidney-lung cross-talk and acute kidney injury. Pediatr Nephrol. 2013;28(12):2239-48.

68 Husain-Syed F, Slutsky AS, Ronco C. Lungkidney cross-talk in the critically ill patient. Am J Respir Crit Care Med. 2016;194(4):40214.

69 Domenech P, Perez T, Saldarini A, Uad P, Musso CG. Kidney-lung pathophysiological crosstalk: its characteristics and importance. Int Urol Nephrol. 2017;49(7):1211-15.

70 Cha RH, Joh JS, Jeong I, Lee JY, Shin HS, Kim $\mathrm{G}$, et al. Renal complications and their prognosis in korean patients with middle east respiratory syndrome-coronavirus from the Central MERS-CoV Designated Hospital. J Korean Med Sci. 2015;30(12):1807-14.

71 Zhou P, Yang XL, Wang XG, Hu B, Zhang L, Zhang W, et al. A pneumonia outbreak associated with a new coronavirus of probable bat origin. Nature. 2020;579(7789):270-3.

72 Hoffmann M, Kleine-Weber H, Krueger N, Mueller MA, Drosten C, Poehlmann S. The novel coronavirus 2019 (2019-nCoV) uses the SARS-coronavirus receptor ACE2 and the cellular protease TMPRSS2 for entry into target cells. bioRxiv. 2020. doi: 10.1101/2020. 01.31.929042.

73 Anti-2019-nCoV Volunteers; Li Z, Wu M, Yao J, Guo J, Liao X, et al. Caution on kidney dysfunctions of 2019-nCoV patients. medRxiv. 2020. doi: 10.1101/2020.02.08.20021212.

74 Puelles VG, Lütgehetmann M, Lindenmeyer MT, Sperhake JP, Wong MN, Allweiss L, et al. Multiorgan and Renal Tropism of SARSCoV-2. N Engl J Med. 2020;383(6):590-592.

75 Santoriello D, Khairallah P, Bomback AS, Xu K, Kudose S, Batal I, et al. Postmortem kidney pathology findings in patients with COVID-19. J Am Soc Nephrol. 2020;31(9):215867.
76 Kuiper JW, Groeneveld ABJ, Slutsky AS, Plötz FB. Mechanical ventilation and acute renal failure. Crit Care Med. 2005;33(6):1408-15.

77 Matthay MA, Aldrich JM, Gotts JE. Treatment for severe acute respiratory distress syndrome from COVID-19. Lancet Respir Med. 2020;8(5):433-4.

78 Ronco C, Reis T, Husain-Syed F. Management of acute kidney injury in patients with COVID-19. Lancet Respir Med. 2020;8(7): P738-42.

79 Adapa S, Aeddula NR, Konala VM, Chenna A, Naramala S, Madhira BR, et al. COVID-19 and renal failure: challenges in the delivery of renal replacement therapy. J Clin Med Res. 2020;12(5):276.

80 Ghani RA, Zainudin S, Ctkong N, Rahman AF, Wafa SR, Mohamad M, et al. Serum IL-6 and IL-1-ra with sequential organ failure assessment scores in septic patients receiving high-volume haemofiltration and continuous venovenous haemofiltration. Nephrology. 2006;11(5):386-93.

81 Vasudevan A, Mantan M, Krishnamurthy S, Pais P, Mathew G, Hari P, et al. Managing children with renal diseases during COVID-19 pandemic. Indian Pediatr. 2018;57(7): 641-51.

82 Chua HR, MacLaren G, Choong LH, Chionh CY, Khoo BZE, Yeo SC, et al. Ensuring sustainability of continuous kidney replacement therapy in the face of extraordinary demand: lessons from the COVID-19 pandemic. Am J Kidney Dis. 2020;76(3):392-400.

83 Reddy YNV, Walensky RP, Mendu ML, Green N, Reddy KP. Estimating shortages in capacity to deliver continuous kidney replacement therapy during the COVID-19 pandemic in the United States. Am J Kidney Dis. 2020;76(5):696-709.

84 Alberici F, Delbarba E, Manenti C, Econimo L, Valerio F, Pola A, et al. Management of patients on dialysis and with kidney transplant during SARS-COV-2 (COVID-19) pandemic in Brescia, Italy. Kidney Int Rep. 2020;5(5): 580-5.

85 Turani F, Barchetta R, Falco M, Busatti S, Weltert L. Continuous renal replacement therapy with the adsorbing filter oXiris in septic patients: a case series. Blood Purif. 2019; 47(Suppl 3):1-5.

86 Yang X, Jin Y, Li R, Zhang Z, Sun R, Chen D. Prevalence and impact of acute renal impairment on COVID-19: a systematic review and meta-analysis. Crit Care. 2020;24(1):356.

87 Brienza N, Puntillo F, Romagnoli S, Tritapepe L. Acute kidney injury in coronavirus disease 2019 infected patients: a meta-analytic study. Blood Purif. 2020;50(1):35-41.

88 Kunutsor SK, Laukkanen JA. Renal complications in COVID-19: a systematic review and meta-analysis. Ann Med. 2020 Nov;52(7): $345-53$. 
89 Hansrivijit P, Qian C, Boonpheng B, Thongprayoon C, Vallabhajosyula S, Cheungpasitporn $\mathrm{W}$, et al. Incidence of acute kidney injury and its association with mortality in patients with COVID-19: a meta-analysis. J Investig Med. 2020 Oct;68(7):1261-70.

90 Lim MA, Pranata R, Huang I, Yonas E, Soeroto AY, Supriyadi R. Multiorgan failure with emphasis on acute kidney injury and severity of COVID-19: systematic review and meta-analysis. Can J Kidney Health Dis. 2020; 7:2054358120938573.
91 Shao M, Li X, Liu F, Tian T, Luo J, Yang Y. Acute kidney injury is associated with severe infection and fatality in patients with COVID-19: a systematic review and meta-analysis of 40 studies and 24,527 patients. Pharmacol Res. 2020;161:105107.

92 Robbins-Juarez SY, Qian L, King KL, Stevens JS, Husain SA, Radhakrishnan J, et al. Outcomes for patients with COVID-19 and acute kidney injury: a systematic review and metaanalysis. Kidney Int Rep. 2020;5(8):1149-60.

93 Zhang Z, Zhang L, Zha D, Hu C, Wu X. Clinical characteristics and risks of Chinàs 2019 novel coronavirus patients with AKI: a systematic review and meta-analysis. Ren Fail. 2020;42(1):926-31.
94 Fu EL, Janse RJ, de Jong Y, van der Endt VHW, Milders J, van der Willik EM, et al. Acute kidney injury and kidney replacement therapy in COVID-19: a systematic review and meta-analysis. Clin Kidney J. 2020;13(4): 550-63.

$95 \mathrm{Wu}$ T, Zuo Z, Kang S, Jiang L, Luo X, Xia Z, et al. Multi-organ dysfunction in patients with COVID-19: a systematic review and meta-analysis. Aging Dis. 2020;11(4):874-94. 